\title{
Review of the Islanding Phenomenon Problem for Connection of Renewable Energy Systems
}

\author{
Hèctor Beltran, Francisco Gimeno, Salvador Seguí-Chilet and Jose M. Torrelo \\ Instituto de Tecnología Eléctrica \\ Av. Juan de la Cierva, 24 - Parc Tecnològic 46980 Paterna, València (Spain) \\ Phone/Fax number: 0034 961366670/961366680 \\ e-mail: \{Hector.Beltran; fjose.gimeno; salvador.segui; jmanuel.torrelo@itenergia.com\}
}

\begin{abstract}
As distributed generators increase their importance on the electric power system, more and more parameters have to be controlled in order to assure the proper operation of the utility. One of the main problems encountered with this kind of generation is the potential formation of islands which could keep working in a normal way even if the utility grid has failed. Many methods have been developed to prevent this situation and they have been classified into three groups: passive, active and methods based on communication systems. This paper checks the validity of some of the active and passive anti-islanding methods. Some of them are shown to work properly with any kind of utility and local loads in the potential island. On the other hand, some others would not disconnect the power generator when the total power of the local load fits that of the generator.
\end{abstract}

\section{Key Words}

Anti-islanding methods, renewable energies, dispersed generation, grid-tied inverters.

\section{Introduction}

Connections of renewable power generators to the utility are changing the structure of the electric power system (EPS). The system is evolving from a tree structure with the generation produced by big power plants to a net structure plenty of small distributed points of generation. These distributed generators (DG) offer the possibility to combine dispersed generation with local energy storage and use, reducing the energy losses produced along the transport and distribution lines and incrementing in this way the EPS effectiveness as well as the power quality.

Some technical requirements have to be established for the connection to the utility of the DG. One of the most important problems to fix is related with the potential generation of islands. As can be observed in Fig. 1, if the EPS fails and the DG keeps on working in normal operation, energizing distribution lines and local loads connected to it, an electric isolated island is formed. This problem, known as islanding operation, is to be avoided since it could involve important and serious consequences. From the EPS side, security measures have to be adopted in order to ensure the safety of the personnel working on the utility and to guarantee the reliability of the utility grid.

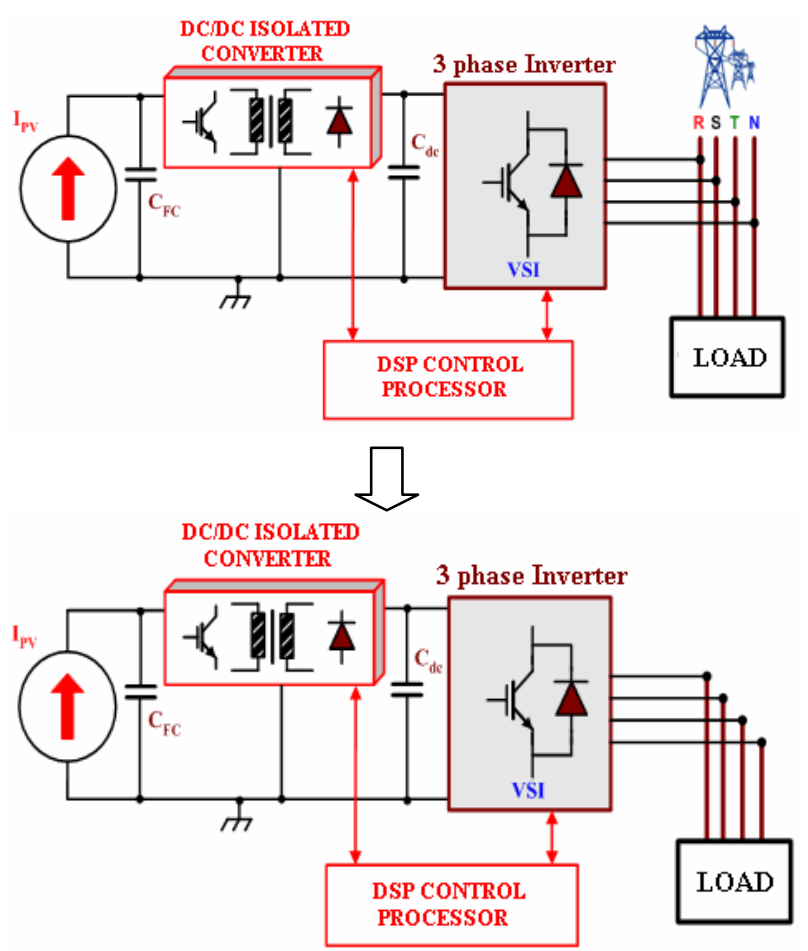

Fig. 1. Formation of an island (DG + Local loads).

Islanding operation keeps a region of the utility, the island connected to the DG, energized. This is hazardous for line operators who could suppose it is disconnected. Moreover, a long duration of the island could produce conflict in case the automatic reclosing of the utility protection devices. This is the case when the reconnection is done before the island has been extinguished. An island could get desynchronized during 
the stand alone period of operation, forcing the protections to fail again and being potentially dangerous for the electronic equipment due to the apparition of short-circuits at the moment of reconnection [1].

The recently increase on DG connected to the utility makes it interesting to further analyze the anti-islanding methods. The knowledge of the problem and the ways to act against is fundamental for the future development the EPS. This paper tries to resume and evaluate, by means of simulation, the existing methods to prevent islanding operation of dispersed generators.

\section{Anti-islanding methods}

A large number of methods for detecting the islanding condition are used. Requirements for the performance of these methods have been spelled out by the International Electrotechnical Commission (IEC), the Underwriters Laboratories Inc. (UL), the Institute of Electrical and Electronics Engineers (IEEE) and several other "National Standards".

The typical DG where the anti-islanding methods have to be implemented is shown in Fig. 2. It is the case of a photovoltaic (PV) generator connected to the EPS. The components forming the system are: the PV panel, the power inverter, the isolation transformer and the parallel local load.

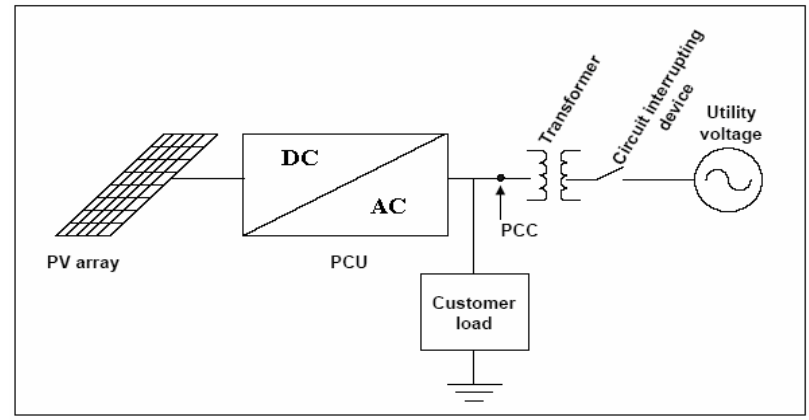

Fig. 2. PV grid connected generator.

Currently, the anti-islanding methods are clearly grouped into three categories as a function of their operating mode. These three categories are:

- Passive methods resident in the grid tied inverter.

- Active methods resident in the grid tied inverter.

- Methods not resident in the DG but communicating the DG and the utility.

\section{a. Passive methods}

This kind of methods lies in the inverter. They are base on the monitoring of certain characteristic parameters in the point of common coupling (PCC). The anti-islanding method causes the disconnection of the inverter from the utility grid under fault conditions when the parameter monitored, different for each method, gets out of the control range considered as usual during the normal operation. The principal ones are:

- OVP/UVP (Over Voltage Protection / Under Voltage Protection) - Controls the PCC voltage value and compares it with normative limits [2] to [7].
- OFP/UFP (Over Frequency Protection / Under Frequency Protection) - Controls the frequency of the voltage signal at the PCC every zero crossing comparing with limits [8], [9] and [10].

- Distortion detection - Checks the THD at the PCC and compares it with limits [6], [11] and [12].

- Phase jump - Controls if there has been a phase jump during each cycle $\rightarrow$ Angle between V and I in PCC.

\section{b. Active methods}

Active methods residing in the inverter to detect the island operation mode introduce deliberated changes or disturbances to the AC output [13] and [14]. Besides, certain parameters are monitored at the PCC in order to detect if the generator is functioning in island-mode or grid-connected mode. If the perturbation introduced by the inverter affects to the AC output characteristics further than the established limits, considered as normal utility fluctuations, the control circuit, or even the voltage and frequency protections in case of getting out of range, disconnects the power generator. On the other hand, if the perturbation leads to no changes in the PCC, the DG can assume the EPS is still on.

By means of the perturbation the response of active methods is faster and more effective than that of the passive methods, reducing the non-detection zone (NDZ) where the DG keeps on working once the utility grid has been disconnected. This NDZ depend mainly on the local loads connected to the DG [8]. The closer the active power consumed by these loads is to the active power supplied by the DG, the higher the probability to form a island. In the same way, as the resonant frequency of the local load approaches the EPS frequency $(50 \mathrm{~Hz})$ the potential formation of islands increases.

The main active methods used for preventing the islanding operation are:

- Impedance measurement - Introduces changes on the injected current to check the variation in voltage experienced at the PCC [6], [15] and [16].

- Slip Mode Frequency Shift (SMS) - The reference angle between current and voltage at the PCC is programmed as a function of the voltage frequency in the cycle immediately before [2], [8] and [17].

- Active Frequency Drift (AFD) - Introduces a current with a frequency slightly higher than that of the voltage at the PCC, giving way to death times modelled by a parameter called chopping fraction [2],[8],[9],[15],[18],[19],[20],[22] and [23].

- Sandia Frequency Shift (SFS) - Similar to the previous one, utilizes a different formula to generate the frequency of the current [1], [19], [21] and [22].

- Sandia Voltage Shift (SVS) - This method applies a feedback to the voltage at the PCC, giving way to a current proportional the value of this voltage [1], [21] and [22].

- Phase Jump (FJ) - Similar to AFD, promotes phase jumps every certain number of current cycles to test if the voltage wave experiences the same jump. 
- Automatic Phase-Shift (APS) - It introduces a permanent delay between $\mathrm{V}$ and I with certain steps every 10 cycles [2].

- Reactive Power Variation (RPV) - Based on the permanent change of power injected to the EPS [25].

- MSD systems - Complex systems that use several methods such as OVP/UVP, OFP/UFP and impedance measurement. From the monitoring of different parameters decides the disconnection.

\section{c. Methods between EPS and DG.}

Methods not resident in the DG side but implemented on the EPS side are much complicated and expensive.

The most important ones can be summarized as:

- Introduction of impedance - A small impedance, normally capacitive, is placed after the PCC on the EPS side. It only gets connected when the breaker DG-EPS is opened, unbalancing the local loads [26].

- PLC Communication - Uses the "Power Line Communications Carrier" technology to test if the DG is working isolated [27] and [28].
- SCADA Systems - With the help of a Supervisory Control and Data Acquisition System the EPS is checked and the potential islands detected [27].

\section{Simulation results}

From all the methods exposed, just some of them have been simulated. Those are: OVP/UVP, OFP/UFP, THD detection and AFD.

For the developing of the process of simulations, the software Matlab/Simulink has been used. Specifically, it has been used one of the libraries of this software called SimPowerSystems (focused on electrical power systems).

With the help of some predefined modules as well as some new ones and a couple of programmed blocks, a DG connected to the EPS can be easily implemented. For the case under study, a PV system connected to grid via a three phase connection has been created. The block diagram of the system resulting from the design can be observed in Fig. 3.

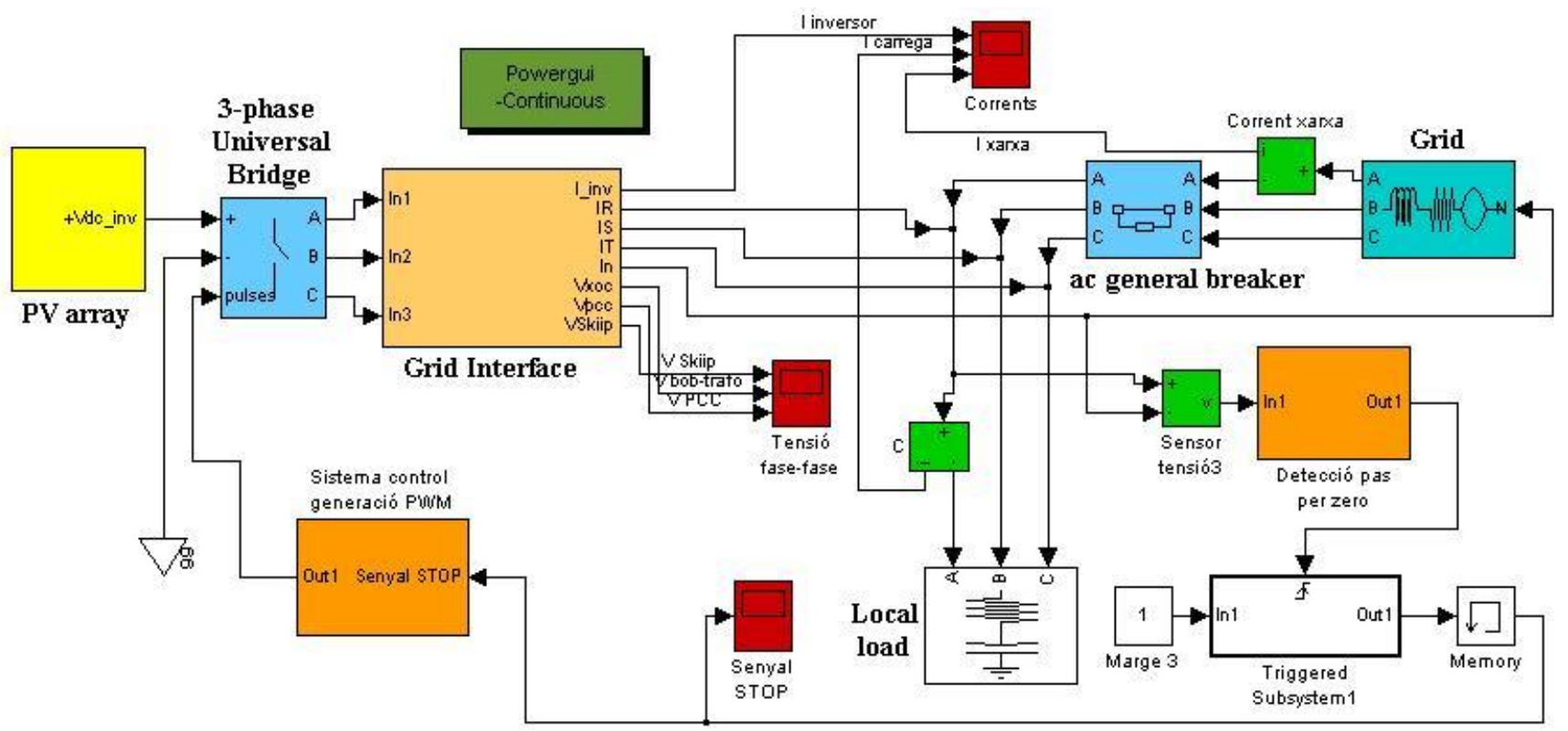

Fig. 3. Model used to simulate the methods.

This model is formed by a PV panel, named "PV array", a block representing the inverter, "3-phase Universal Bridge", a big one called "grid interface" which comprehends the isolation transformer and the connection coils, another one with name "ac general breaker" representing the block which produces the failure of the EPS, a load in parallel with it ("Local load"), the block for the EPS ("Grid"), and finally all the blocks corresponding to the control system.

With this block diagram, different methods (passive and active) have been simulated modifying the control blocks. These variations have been done to adapting the model to the functioning mode of the respective methods.

For each of the simulation procedures, the period analyzed is of 0.25 seconds, starting the simulation with the DG connected to the EPS and producing energy. After 0.13 seconds the utility has been disconnected and the response of the model registered for the different methods. The detection of the island has been observed and the subsequent disconnection of the inverter checked. Fig. 4 summarizes the time intervals described before.

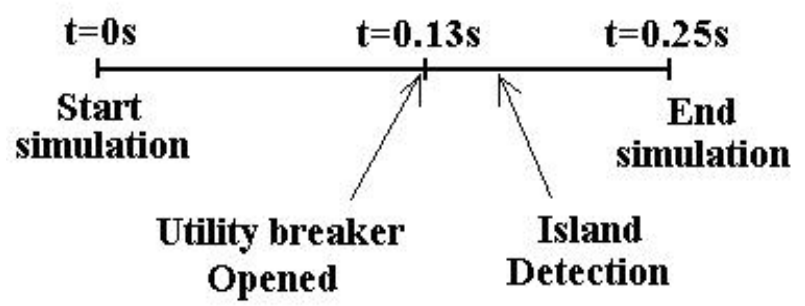

Fig. 4. Time line of the simulations performed. 
The voltage waves obtained after the inverter and at the PCC can be observed in the following Fig. 5 and Fig. 6 respectively. These waves correspond to the typical PWM modulation applied to the inverters in the first case, and to the EPS voltage till the moment of disconnection in the second case. In this second figure, it can be observed the transient disequilibrium experienced by the voltage after disconnection when the value is fixed by the DG.

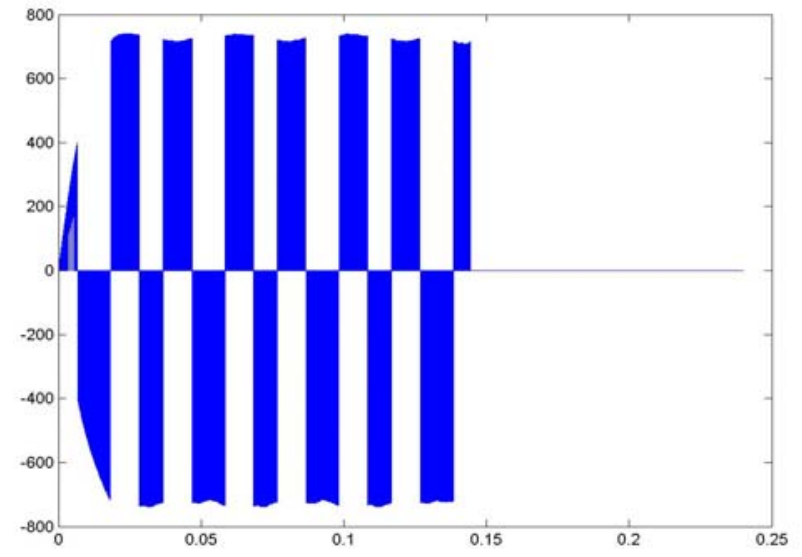

Fig. 5. Voltage obtained after the IGBTs' bridge.

Fig. 5 and Fig. 6 are representative for most of the responses of the different methods. When the EPS gets disconnected, the voltage at the PCC gets unstable exceeding some of the limits established on the different parameters as a function of the method implemented. The control system launches then a STOP signal, at around $0.16 \mathrm{~s}$ in the previous case, which produces the interruption of the normal functioning mode of the inverter. Thus, the system gets stopped and the voltage at the PCC drops to zero.

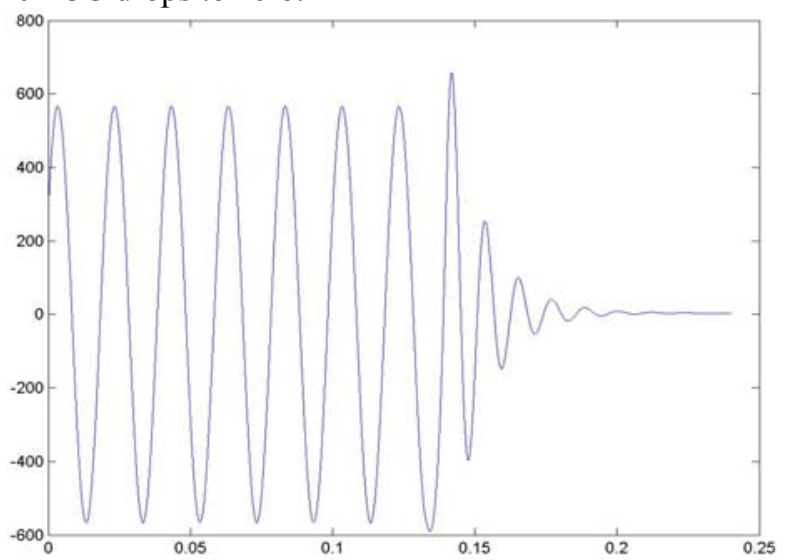

Fig. 6. Voltage simulated at the PCC (Phase to phase).

\section{a. OVP/UVP.}

The Over Voltage Protection / Under Voltage Protection method controls the PCC voltage value and compares it with certain established limits. When the control system registers a rms voltage higher or lower than that permitted at the PCC, it produces the STOP signal. The value of this voltage for the simulation performed is represented in Fig. 7. After disconnection of the EPS, $\mathrm{t}=0.13 \mathrm{~s}$, the voltage increases causing the disconnection of the DG at around $\mathrm{t}=0.145 \mathrm{~s}$.

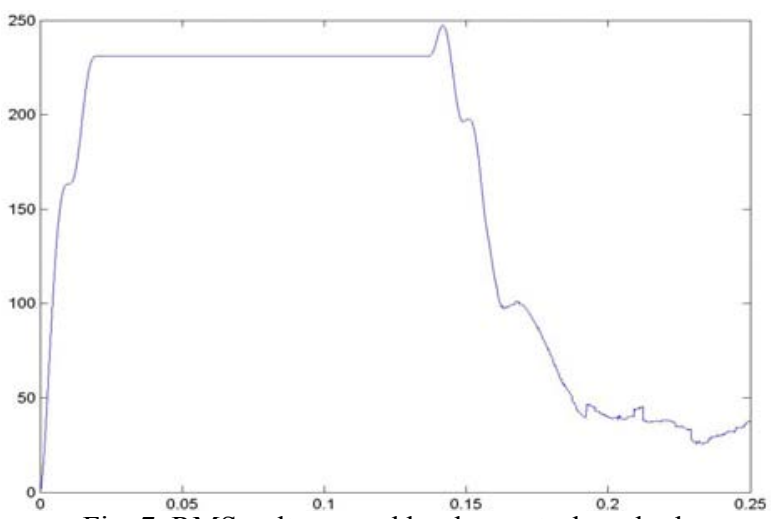

Fig. 7. RMS voltage read by the control method.

\section{b. OFP/UFP.}

The Over Frequency/Under Frequency Protection method controls the frequency of the voltage signal at the PCC every zero crossing, comparing its value with the regulated limits to check it is always kept in between. In the case the calculated frequency fall out of the accepted range the control system would generate the STOP signal to produce the interruption of the generation.

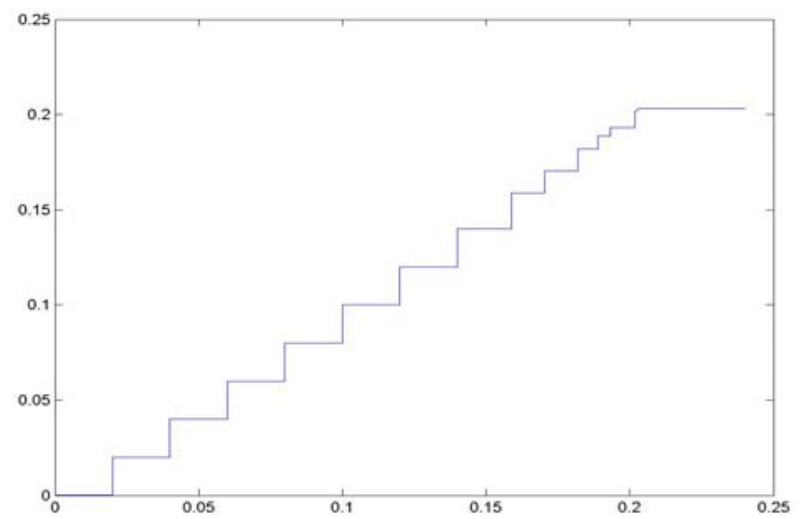

Fig. 8. Stepped signal used by the OFP/UFP control method.

As shown in Fig. 8, every time the voltage crosses zero, the control system registers it, adding one step to the control signal (the value of the step is equal to the increment of time from the last zero-crossing). Till the moment the utility fails, the steps are equal, but after disconnection they get irregular allowing the control system to detect the islanding situation. After disconnection $(\mathrm{t}=0.13 \mathrm{~s})$, the frequency changes appearing the STOP signal at $\mathrm{t} \sim 0.15 \mathrm{~s}$.

\section{c. THD Detection.}

The harmonic distortion detection method checks the voltage THD $\left(\mathrm{THD}_{\mathrm{V}}\right)$ at the PCC and compares it with the established limits as acceptable in the utility. When the utility is connected the $\mathrm{THD}_{\mathrm{V}}$ is fixed at a very low level. But just after disconnection $(t=0.13 \mathrm{~s})$, it increases quite a lot going beyond the accepted level. This produces the disconnection signal of the DG in this antiislanding method. As can be observed in Fig .9, after failure of the EPS the level of harmonic distortion gets incremented and quickly uncontrolled due to resonances between induction coils and capacitors of the local load. 


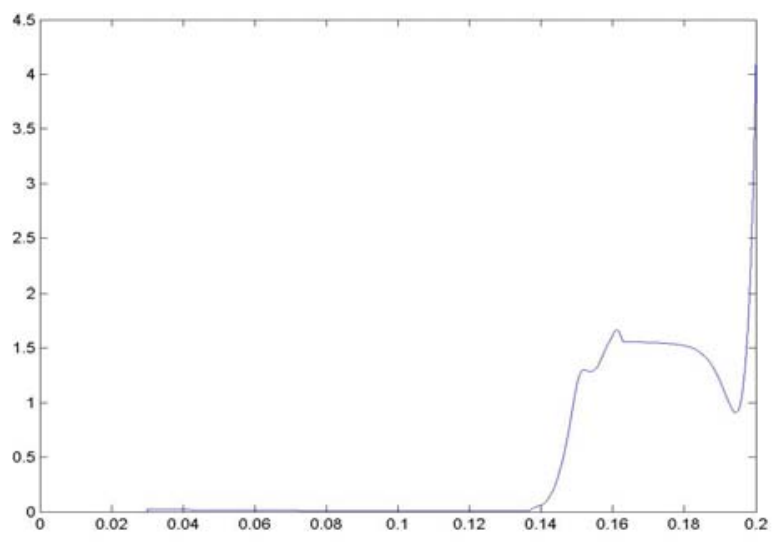

Fig 9.Lecture of the THD extracted by the control system.

\section{d. AFD.}

The Active Frequency Drift method (AFD) introduces a current with a frequency slightly higher than that of the voltage at the PCC. These reference currents give way to death times modelled by a parameter called chopping fraction. This chopping fraction represents the relation between the period of the current wave and the time this wave has a value equal to zero. The shape of the reference currents, with the corresponding death times every 5 cycles can be observed in Fig. 10.

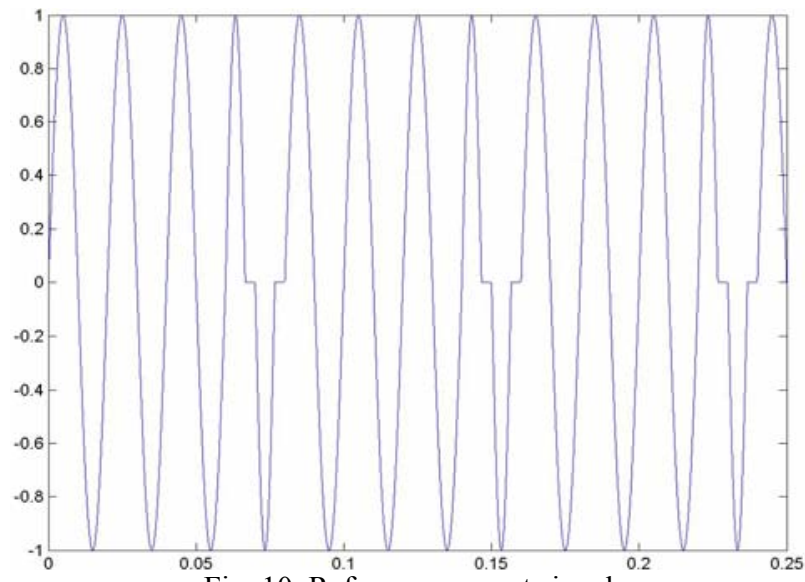

Fig. 10. Reference current signal.

By means of these reference currents, the disconnection of the DG when the utility fails has been checked. The time response depends with this method on the coincidence in time between the utility failure and the special cycle with high frequency imposed to the injection currents. Till the next special cycle the system won't detect the island. In the Spanish regulations, the time of detection and disconnection has to be less than 2 seconds. So, the high frequency cycle is not introduced very often (e.g. every 0.5 seconds) in order not to reduce the power quality that much. The introduction of the perturbation reduces a lot the NDZ, offering a higher security implementation and that is the key of the AFD.

\section{Experimental procedure}

Apart from the simulations, some experiments have been performed. The hardware used to build the system and test the methods with a linear load, in steady-state conditions, contains the following blocks:

- Power source: A $3 \mathrm{~kW}$ DC current source which simulated the DC power source of PV panels complemented by a maximum power point tracking system (PMP) [29].

- Power stage: six IGBT transistors and their drivers, all included in the Skiip ${ }^{\circledR}$ 342GD1230-314CTV module. (Fig. 11)

- DC bus: formed of a serial/parallel capacitor array with a total capacitance of $7 \mathrm{mF} ; 800 \mathrm{~V}$ of maximum voltage and accessible mid-point for the connection of the neutral wire.

- Measurements: isolated hall sensors were selected for measuring current and voltage.

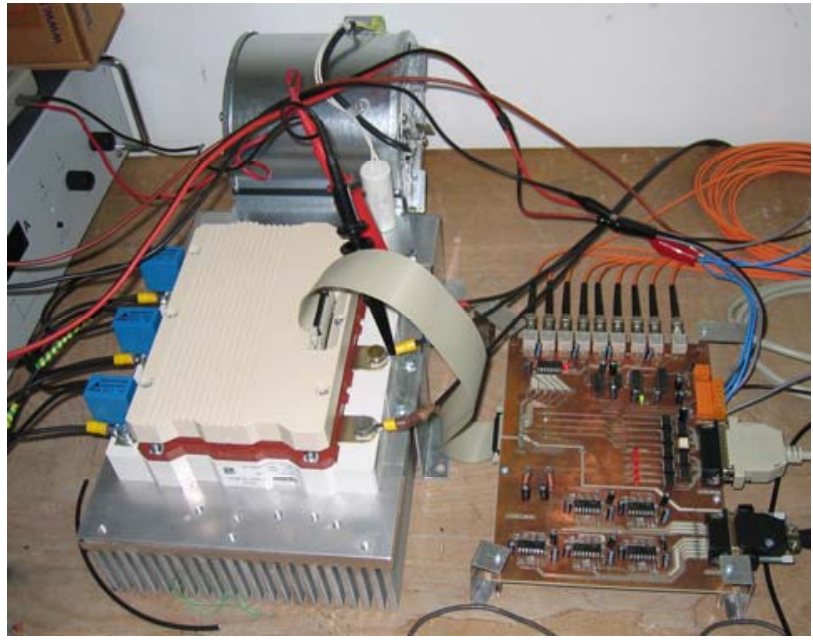

Fig. 11. IGBTs bridge and control adaptation PCB.

- Shift level circuit: consisting of two sub-circuits with different functions:

- The first circuit adapts the level of the PWM signals between the DSP (TTL at $3.3 \mathrm{~V}$ ) and the Skiip ${ }^{\circledR}$ module (CMOS at 15V).

- The second circuit adapts the level of the analogue signals that measure the current in the three legs of the inverter and the Skiip ${ }^{\circledR}$ module temperature and changes the analogue levels to match the input characteristics of the ADC included in the DSP.

- Digital control stage: a fixed point DSP (TMS320LF2407) is used for the generation of PWM signals that trigger the six IGBT in the threephase inverter [3]. The triggering signals are obtained by comparing the output current in each inverter leg with the reference current generated by the DSP and established according to the UTEP.

- Development control stage: consists of a PC and a Texas Instruments XDS510P emulator. The control routine algorithm are been developed in $\mathrm{C}$ and in assembler.

- Three adaptive current $8 \mathrm{mH}$ inductors to smooth the current waves obtained in the inverter bridge, Fig.13.

- Three single phase transformers to provide galvanic isolation from the utility in the point of connection. 


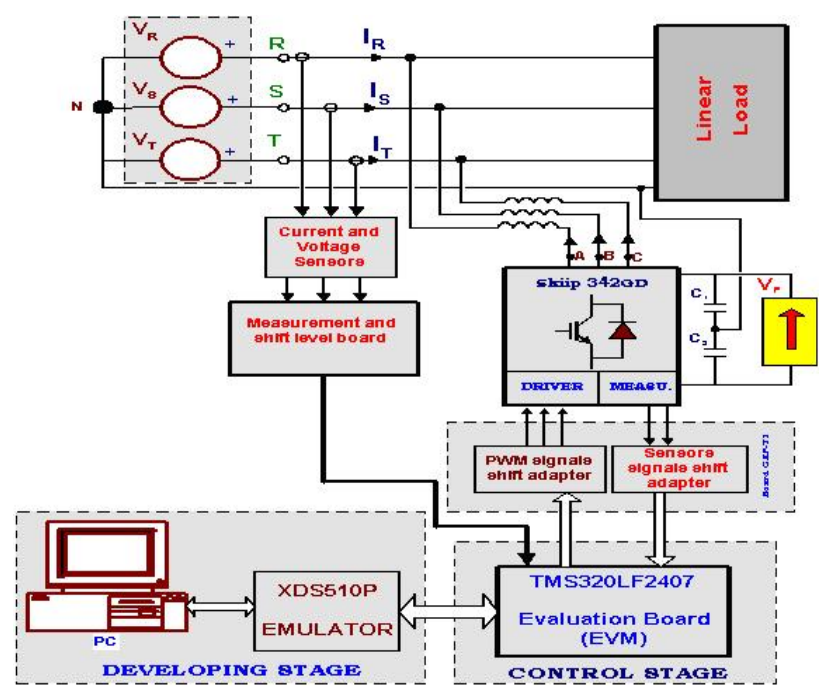

Fig. 12. Block diagram of the full hardware system.

The global system diagram can be observed in figure 12 .

Before injecting current to the utility, the system has been tested with a local load composed by 18 resistive linear power loads which are combined to obtain the maximum power available from the source $(3 \mathrm{~kW})$, Fig. 13. A total ac rms maximum current of $7 \mathrm{~A}$ has been obtained. When injecting to the utility the current generated has been around $8 \mathrm{~A}$ rms.

The control of the system has been established with the DSP TMS320LF2407. The time response in case of island formation is important and limited by the IEEE standards [30]. The islanding control allows detecting the abnormal operation and produces the generator disconnection within a very short time. With this system, a series of tests have been carried on to check the performance of the OVP/UVP and OFP/UFP methods. Some others are being implemented nowadays and will be analyzed in future months.

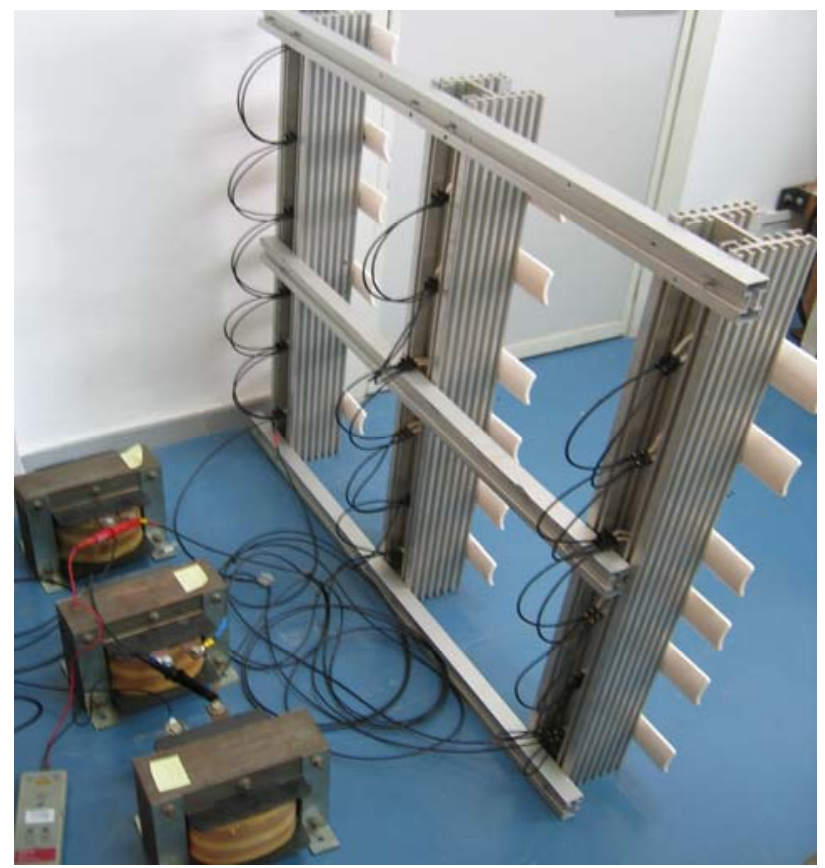

Fig. 13. Customer load and inverter output inductors.

\section{Conclusions}

The paper introduces many anti-islanding detection methods, clarifying the differences among them and the advantages of each one. Simulations using Matlab / Simulink have been performed as well as experiments testing some passive methods.

The simulations have modeled a photovoltaic application power system (PV), connected to the EPS through an inverter. Different anti-islanding algorithms have been programmed in the PC model to check their response under different working conditions. Results obtained by simulation agree with theoretical behaviour of the methods.

The large number of existing methods demonstrates the need to look for a major uniformity within the international regulations regarding electrical systems and electric power connections.

Although passive methods should be enough protection in most cases, active methods should be added to all the new systems to ensure the correct functioning. AFD method is suggested as one of the best. It has been largely developed and enhanced in order to get a high quality performance level. On the other hand, MSD systems offer a good protection and ore those being implemented in Germany and Austria.

\section{References}

[1] Sigifredo Gonzalez, Russell Bonn, Jerry Ginn "Removing Barriers to Utility Interconnected Photovoltaic Inverters" 28th IEEE Photovoltaic Specialist Conference, Anchorage, AK, Sept 15-22, 2000.

[2] Khanchai Tunlasakun, Krissanapong Kirtikara, Sirichai Thepa, Veerapol Monyakul3, "CPLD - Based Islanding Detection for Mini Grid Connected Inverter in Renewable Energy", 0-7803-8560-8/04 (C) 2004 IEEE.

[3] Michael E. Ropp, Miroslav Begovic, Ajeet Rohatgi, Gregory A. Kern, R. H. Bonn, S. Gonzalez "Determining the Relative Effectiveness of Islanding Detection Methods Using Phase Criteria and Nondetection Zones" IEEE Transaction on Energy Conversion, Vol. 15, № 3, September 2000, 0885-8969/00 @ 2000 IEEE.

[4] Zhihong Ye, Amol Kolwalkar, Yu Zhang, Pengwei Du, Reigh Walling, "Evaluation of Anti-Islanding Schemes Based on Non Detection Zone Concept" 0-7803-7754-0/03 (C) 2003 IEEE.

[5] H.Zeineldin, E.F.El-Saadany, M.M.A.Salama, "Impact of DG Interface Control on Islanding Detection", 0-78039156-X/05 (C) 2005 IEEE.

[6] H. Haeberlin, J.Graf, "Islanding of grid-connected PV Inverters: Test Circuit and some Test Results", 2nd World Conference on Photovoltaic Solar Energy Conversion, Vienna, Austria, 1998.

[7] Mamadou L.Doumbia, Kodjo Agbossou, Tapan K.Bose, "Islanding Protection Evaluation of Inverter-Based GridConnected Hybrid Renewable Energy System",0-78038253-6/04@2004 IEEE.

[8] Huili Sun, Luiz A.C. Lopes, Zhixiang Luo, "Analysis and Comparison of Islanding Detection Methods Using a New Load Parameter Space" The 30th annual conference of IEEE Industrial Electronics Society, November 2004, Busan, Korea, 0-7803-8730-9/04 (C) 2004 IEEE. 
[9] M.E.Ropp, M.Begovic, A.Rohatgi, "Analysis and performance assessment of the active frequency drift method of islanding prevention", IEEE Transactions on Energy Conversion, Vol. 14, No. 3, September 1999, 0885-8969/99 (C) 1998 IEEE

[10] Khanchai Tunlasakun, Krissanapong Kirtikara, Sirichai Thepa, Veerapol Monyakul, "A microcontroller based islanding detection for grid connected inverter" The 47th IEEE Midwest Symposium on Circuits and Systems, 07803-8346-X/04 (C) 2004 IEEE.

[11] David G. Infield, Peter Onions, Anton D. Simmons, Gordon A. Smith, "Power Quality from Multiple GridConnected Single-Phase Inverters", IEEE Transactions on Power Electronics, Vol. 19, No5, September 2004, 08858977/04 (C) 2004 IEEE.

[12] H.Zeineldin, M.I.Marei, E.F.El-Saadany, M.M.A.Salama, "Safe Controlled Islanding of Inverter Based Distributed Generation", 2004 35th Annual IEEE Power Electronics Specialists Conference Aachen, Germany, 2004.

[13] Guo-Kiang Hung, Chih-Chang Chang, and Chern-Lin Chen "Automatic phase-shift method for islanding detection of grid-connected photovoltaic inverters" IEEE Transactions on Energy Conversion, Vol.8, $\mathrm{N}^{\circ}$.1March 2003

[14] S. Mekhilef, N.A. Rabim, "Implementation of GridConnected Photovoltaic System with Power Factor Control \& Islanding Detection" 2004 35th Annual IEEE Power Electronics Specialists Conference Aachen, (Germany)

[15] Jun Motohashi, Tadao Ishikawa, Chikashi Nakazawa, Takashi lchinose, "Comparison of Digital Simulation and Field Test Result of Islanding Detection System for Synchronous Generators", 0-7803-4403-0/981 C 1998 IEEE.

[16] A.Kotsopoulos, J.L.Dum, M.A.M.Hendriw, P.J.M.Heskes, "Islanding Behaviour of Grid-Connected PV Inverters Operating Under Different Control Schemes", 0-78037262-X/02 @ 2002 IEEE.

[17] Michael E. Ropp, Miroslav Begovic, Ajeet Rohatgi, Gregory A. Kern, R. H. Bonn, S. Gonzalez "Determining the Relative Effectiveness of Islanding Detection Methods Using Phase Criteria and Nondetection Zones" IEEE Transaction on Energy Conversion, Vol. 15, №. 3, September 2000, 0885-8969/00 (C) 2000 IEEE.

[18] Gwon-jong Yu, Jeong-Hoon So, Young-Seok Jung, Juyeop Choi, "Boundary Conditions of Reactive-PowerVariation Method and Active-Frequency-Shift Method for Islanding Detection of Grid-connected PV Inverters", 07803-8707-4/05 (C) 2005 IEEE.
[19] Michael E. Ropp, Miroslav Begovic, Ajeet Rohatgi, Gregory A. Kern, R. H. Bonn, S. Gonzalez "Determining the Relative Effectiveness of Islanding Detection Methods Using Phase Criteria and Nondetection Zones" IEEE Transaction on Energy Conversion, Vol. 15, № 3, September 2000, 0885-8969/00 (C) 2000 IEEE.

[20] Raymond M.Hudson, Tony Thome, Fereydoun Mekanil, Michael R.Behnke, Sigifredo Gonzalez, Jerry Ginn, "Implementation and Testing of anti-islanding algorithms for IEEE 929-2000", 0-7803-7471-1/02 (C) 2002 IEEE .

[21] Vinod John, Zhihong Ye, Amol Kolwalkar, "Investigation of Anti-Islanding Protection of Power Converter Based Distributed Generators Using Frequency Domain Analysis", IEEE Transactions on Power Electronics, Vol. 19, Nº5, September 2004, 0885-8993/04 (C) 2004 IEEE.

[22] Achim Woyte, Ronnie Belmans, Johan Nijs, "Islanding of Grid-Connected AC module Inverters", 0-7803-5772-8/00 (C) 2000 IEEE.

[23] Achim Boyte, Ronnie Belmans, Johan Nijs, "Testing the Islanding Protection Function of Photovoltaic Inverters", IEEE Transaction on Energy Conversion 18, March 2003, p.157-162.

[24] "Islanding Testing Presentation", Sandia National Labs.

[25] Youngseok Jung, Junghun So, Gwonjong Yu, Jaeho Cho, "Modelling and Analysis of Active Islanding Detection Methods for Photovoltaic Power Conditioning Systems", 0-7803-8253-6/04 C2004 IEEE.

[26] Akio Kitamura, Hiromu Matsuda, Fumio Yamamoto, Takehiko Matsuoka, "Islanding phenomenon of grid connected PV systems", 0-7803-5772-8/00 (C) 2000 IEEE.

[27] Lauri Kumpulainen, Kimmo Kauhaniemi, "Distributed Generation and Reclosing Coordination".

[28] M. E. Ropp, K.Aaker, J.Haigh, N.Sabbah, "Using Power Line Carrier Communications to Prevent Islanding", 07803-5772-8/00 (C) 2000 IEEE.

[29] E. Daroqui, J. Soler, S. Seguí, F. J. Gimeno, S. Orts, "Direct coupling between photovoltaic module and a PWM converter". 2004 IEEE 35th Annual Power Electronics Specialist Conference, Aachen (Germany).

[30] IEEE Std 929-2000 Recommended Practice for Utility Interface of Photovoltaic (PV) Systems, Sponsored by IEEE Standards Coordinating Committee 21 on Photovoltaics, Published by the IEEE, New York, NY April 2000. 